\title{
Sentencias Interpretativas en Materia Ambiental
}

\author{
Mario Peña Chacón ${ }^{1}$ \\ Universidad de Costa Rica, San José, Costa Rica.
}

(Enviado: Agosto, 2014 - Publicado: Diciembre, 2014)

\section{Resumen:}

La técnica de las sentencias interpretativas se posiciona como un instrumento esencial e imprescindible con el que cuenta el juez constitucional para garantizar el orden público ambiental y con ello mejorar la eficacia del derecho ambiental.

Palabras Claves: Sentencias interpretativas; Sentencias normativas; Método de interpretación conforme a la constitución.

\begin{abstract}
:
The art of interpretative judgments is positioned as an essential and indispensable instrument that the constitutional judge has to ensure environmental public order and thereby improve the effectiveness of environmental law.

Keywords: Interpretative judgments; Normative judgments; Under the constitution interpretation method.

* Este artículo es producto del Proyecto de Investigación denominado "Las clínicas del Derecho Ambiental y Gestión de Riesgos Climáticos a través de una cultura jurídica de la sostenibilidad y no regresión” inscrito ante la Vicerrectoría de Investigación y el Instituto de Investigaciones Jurídicas de la Universidad de Costa Rica bajo el código 722-B3-193.
\end{abstract}

\section{Introducción}

El carácter finalista del derecho ambiental, su condición de derecho humano fundamental y la consolidación de sus principios generales, en especial los de progresividad, no regresión y precautorio, obligan un nuevo enfoque hermenéutico donde el exégeta deberá tener como norte su espíritu, finalidad y en especial, su objetivo primordial de tutela de la vida, la salud y el equilibrio ecológico, en armonía con el derecho a un ambiente sano y ecológicamente equilibrado previsto en el numeral 50 constitucional.

El operador jurídico debe buscar aquella interpretación que permita aplicar la norma para "proteger más y contaminar menos", "aumentar la biodiversidad y disminuir la contaminación" sin perder de vista la necesidad de un "uso racional de los recursos naturales" que satisfaga las necesidades de las actuales y futuras generaciones.

Ante esta realidad, la técnica de las sentencias interpretativas y el método de interpretación conforme al bloque de constitucionalidad se constituyen en herramientas procesales fundamentales con las que cuenta el juez constitucional que le permiten

\footnotetext{
${ }^{1}$ Autor para correspondencia. Email: mariopenachacon@gmail.com
} 
viabilizar, en el plano de la eficacia, la prestación jurisdiccional y la ratio essendi de la normativa ambiental.

\section{Sentencias Interpretativas Constitucionales}

El artículo 1 de la Ley de Jurisdicción Constitucional establece como objeto de esta jurisdicción garantizar la supremacía de las normas y principios constitucionales y del Derecho Internacional o Comunitario, su uniforme interpretación y aplicación, así como los derechos y libertades fundamentales consagradas en la Constitución Política o en los instrumentos internacionales sobre derechos humanos. Además, el numeral 13 de la citada norma le otorga a la jurisprudencia y precedentes constitucionales fuerza vinculante erga omnes, salvo para sí misma.

Por su parte, la Ley Orgánica del Poder Judicial en su numeral 8 inciso primero, prohíbe a los funcionarios judiciales aplicar leyes y otras normas o actos de cualquier naturaleza, contrarios a la Constitución Política o al Derecho Internacional o Comunitario, ni interpretarlos o aplicarlos de manera contraria a los precedentes o la jurisprudencia de la Sala Constitucional.

De los artículos antes expuestos es posible derivar el principio de supremacía o prioridad jerárquica y cualitativa de la Constitución Política, así como su carácter normativo, el cual obliga interpretar y aplicar el ordenamiento jurídico de conformidad con las normas, principios, valores y jurisprudencia constitucionales, elementos que se convierten en parámetros hermenéuticos que fijan la constitucionalidad de las demás normas que integran el sistema jurídico.

De esta forma y en palabras de ARGUEDAS RAMIREZ, ${ }^{2}$ la Sala Constitucional actúa, en el sistema costarricense, como intérprete supremo de las normas que integran el bloque de constitucionalidad y de las restantes de rango inferior cuando su interpretación resulte imprescindible para dar cabal cumplimiento (plenitud) a cualquiera de las funciones propias del órgano de la jurisdicción constitucional.

En aplicación de las facultades otorgadas tanto por la Ley de Jurisdicción Constitucional como por la Ley Orgánica del Poder Judicial, la Sala Constitucional mediante la técnica de las sentencias interpretativas, dispone la interpretación constitucionalmente válida de las normas jurídicas, descarta todas aquellas que considere que violentan las normas, principios, valores y jurisprudencia constitucionales, o bien afirma expresa $o$ implícitamente la constitucionalidad de una parte del contenido normativo derivado conjuntamente de un texto legal. ${ }^{3}$

Por medio de la técnica de las sentencias interpretativas, la Sala Constitucional reafirma la constitucionalidad de la norma sujeta a impugnación, o bien de una parte de ella,

\footnotetext{
${ }^{2}$ Arguedas Ramírez, Carlos Manuel, La interpretación judicial y la Sala Constitucional de la Corte Suprema de Justicia de Costa Rica, en Revista de Estudios Constitucionales, volumen 1, número 1, Chile, 2003, disponible en: $\underline{w w w} \cdot$ redalyc.org/articulo.oa? $i d=82010120$

3 Arce Gómez, Celin Eduardo, tesis doctoral Sala Constitucional legislador positivo, disponible en: http://unpan1.un.org/intradoc/groups/public/documents/icap/unpan047691.pdf
} 
señalando cuál es la interpretación y aplicación conforme con el derecho de la Constitución. Se salva, efectivamente, la constitucionalidad de la norma en cuanto tal, pero a condición de que se interprete y aplique de una determinada forma, sea la que la Sala Constitucional fija. ${ }^{4}$

RUBIO CORREA ${ }^{5}$ señala que este tipo de sentencias están referidas al contenido normativo de las disposiciones de rango de ley que puedan tener más de una interpretación posible. De estas varias interpretaciones, una debe ser acorde con la Constitución y las otras no lo serán. Así pues, una sentencia interpretativa es aquella que elige la interpretación constitucional de una disposición y la establece como obligatoria, señalando que las otras interpretaciones son inconstitucionales.

Para ARCE GÓMEZ, ${ }^{6}$ las sentencias interpretativas constituyen un procedimiento por medio del cual los tribunales constitucionales dejan de cumplir con su función de legislador negativo y tienden a asumir una función de legislador positivo, sea, la de un tribunal creador de normas. Por medio de este instrumento procesal, el juez constitucional puede terminar sustituyendo a la Asamblea Legislativa en su función de creador de normas primarias con eficacia erga omnes.

En esa misma línea, HERNÁNDEZ VALLE ${ }^{7}$ explica que esta técnica interpretativa, bajo determinadas circunstancias, podría suplantar al legislador ordinario, puesto que por esta vía los tribunales constitucionales podrían, so pretexto de interpretar la legislación ordinaria conforme a la Constitución, introducir normas ex novo en el ordenamiento jurídico. ${ }^{8}$

De la mano con la técnica de las sentencias interpretativas constitucionales se encuentra el método de interpretación conforme con la Constitución. Este método interpretativo deriva del carácter normativo y rango superior y supremo dentro del ordenamiento jurídico que ostenta la Constitución Política. El método de interpretación conforme implica que ante varias posibles interpretaciones de una norma jurídica, el juez constitucional debe escoger aquella que mejor armonice con el derecho de la Constitución, absteniéndose en la medida de lo posible, de declarar la inconstitucionalidad de la norma impugnada.

Para GONZÁLEZ BALLAR, ${ }^{9}$ la supresión de una ley o parte de ella del ordenamiento jurídico constituye un "trauma" en el sistema, situación que impone al juez constitucional una actitud madura frente al conflicto planteado. La posibilidad de instaurar

\footnotetext{
4 Solano Carrera, Luis Fernando, A veinte años de la Sala Constitucional: reflexiones sobre impactos, riesgos y desafíos, disponible en:

http://www.estadonacion.or.cr/files/biblioteca_virtual/015/info15cap7.pdf

${ }^{5}$ Citado por Arce Gómez, Celin Eduardo, tesis doctoral Sala Constitucional legislador positivo, disponible en: http://unpan1.un.org/intradoc/groups/public/documents/icap/unpan047691.pdf

6 Arce Gómez, Celin Eduardo, tesis doctoral Sala Constitucional legislador positivo, disponible en: http://unpan1.un.org/intradoc/groups/public/documents/icap/unpan047691.pdf

7 Hernández Valle, Rubén, La interpretación constitucional en Costa Rica, disponible en: http://biblio.juridicas.unam.mx/libros/6/2701/27.pdf

${ }^{8}$ Por no ser el objeto de este estudio, dejaremos que sean los constitucionalistas los que discutan y polemicen respecto al rol de legislador positivo de la Sala Constitucional.

${ }^{9}$ González Ballar y otros, La Sala Constitucional, entre el ser y el deber ser. Perfilando un nuevo juez constitucional, obra pendiente de publicación.
} 
"interpretaciones conformes", es una de las herramientas dogmáticamente reconocidas para mantener la regularidad constitucional sin la gravosa sentencia de inconstitucionalidad; pista que lleva a establecer que el operador jurídico debe encausar su análisis bajo un derrotero: la afectación flagrante, directa y gravosa del texto normativo frente al bloque de constitucionalidad, guías que, de toda suerte, son una garantía de tutela de los derechos fundamentales de los sujetos.

JINESTA LOBO $^{10}$ señala que el método de interpretación conforme se sustenta en una doble presunción: subjetiva de que el legislador realizó su función dentro de los límites constitucionales (favor legislatoris), y objetiva de que la ley se ajusta a los parámetros establecidos por la Constitución (favor legis). Esta última supone que la norma o acto no adolece de ningún vicio que lo invalide y su fundamento radica en la necesidad de conservar el Derecho. Para este autor, el método de interpretación conforme surge del principio favor legitimatis, que pretende conservar el derecho para evitar el denominado horror vacui producido por la anulación de una ley, asegurar la supremacía de la Constitución y respetar la seguridad jurídica. También encuentra fundamento en otros principios tales como el de jerarquía normativa, seguridad jurídica entroncado con los de unidad y coherencia, los que suponen una interpretación coordinada del ordenamiento jurídico para evitar antinomias. También juega un rol importante el principio de la plenitud hermética del ordenamiento jurídico, a efecto de evitar lagunas.

En virtud de que el bloque de constitucionalidad se encuentre compuesto también por el derecho internacional y comunitario, el juez constitucional está obligado a integrar el criterio de interpretación conforme de las normas constitucionales e infra constitucionales a la luz del derecho internacional y del derecho internacional de los derechos humanos.

Según explica FERRER MAC-GREGOR ${ }^{11}$, la cláusula de interpretación conforme contiene un "principio de armonización" entre la Constitución Política y el derecho internacional. Lo anterior significa que el juez constitucional debe procurar una interpretación que permita "armonizar" la "norma nacional y la internacional". No se trata de dos interpretaciones sucesivas (primero la interpretación conforme a la Constitución y luego la interpretación conforme al tratado internacional), sino de una interpretación conforme que armonice ambas. De ahí que esta cláusula cumple con una función hermenéutica de armonización.

A las sentencias interpretativas que llegan a sustituir la voluntad del legislador, y que por tanto se convierten en sentencias normativas, HERNÁNDEZ VALLE ${ }^{12}$ las clasifica en dos clases: las aditivas y las sustitutivas, y éstas últimas las divide a su vez en las que introducen nuevas normas propiamente dichas y las que ponen en vigencia normas derogadas por las declaradas inconstitucionales.

\footnotetext{
${ }^{10}$ Jinesta Lobo, Ernesto, Interpretación y aplicación directa del derecho de la Constitución por el juez ordinario" en Revista Ivstitita, año 10, número 118-119, octubre-noviembre 2006.

${ }^{11}$ Ferrer Mac-Gregor, Eduardo, Interpretación conforme y control difuso de convencionalidad. El nuevo paradigma para el juez mexicano, accesible en: http://biblio.juridicas.unam.mx/libros/7/3033/14.pdf

${ }^{12}$ Hernández Valle, Rubén. La problemática de las sentencias normativas, en La Jurisdicción constitucional y su influencia en el Estado de Derecho San José, EUNED, 1996.
} 
En cuanto a las aditivas HERNÁNDEZ VALLE ${ }^{13}$ expone que son aquellas que se dictan en los casos de inconstitucionalidad por omisión. Se trata, en consecuencia, de una sentencia que declara la inconstitucionalidad, no del texto de la norma o disposición general impugnadas, sino más bien por lo que tales textos o normas no dicen y debieran decir. Respecto a este tipo de sentencias, los tribunales constitucionales tienen dos opciones: crear la norma para el caso concreto, extendiendo el beneficio a los ilegítimamente excluidos, con lo cual entran en el terreno de las sentencias aditivas, o bien se abstienen de hacerlo y dejan que sea el legislador o la Administración, en su caso, los que corrijan la omisión inconstitucional.

Respecto a las sustitutivas, el autor antes citado manifiesta que se trata de sentencias que innovan el ordenamiento preexistente, introduciendo nuevas disposiciones con efectos erga omnes. La característica de las sentencias estimatorias sustitutivas, radica en que el juez constitucional asume el papel de legislador ordinario pues crea normas jurídicas con eficacia erga omnes que sustituyen las declaradas inconstitucionales, ya sea porque el texto original adquiere otro sentido con las palabras o párrafos anulados, o bien porque el juez constitucional le introduce una nueva normativa en sustitución de la anulada. Por su parte, las sentencias constitucionales sustitutivas que ponen en vigencia normas derogadas, se producen en aquellos casos en que la normativa anulada produce un vacío en el ordenamiento que debe ser colmado mientras el legislador dicta la correspondiente normativa sustitutiva.

\section{Sentencias interpretativas en materia ambiental}

En materia ambiental han sido múltiples las sentencias interpretativas constitucionales que, aplicando el criterio de interpretación conforme, han mantenido la vigencia de normas jurídicas impugnadas armonizándolas con los valores, principios y normas constitucionales, especialmente a la luz del artículo 50 constitucional y el derecho internacional.

Como muestra de lo antes expuesto, mediante la resolución 2012-1283, el tribunal constitucional costarricense declaró la constitucionalidad de los artículo 21 y 29 del Decreto Ejecutivo número 35884-MINAET - Reglamento de Perforación del Subsuelo para la Exploración y Aprovechamiento de Aguas Subterráneas - siempre que se interprete que el transcurso de la audiencia sin pronunciamiento de los entes respectivos, no significa su conformidad ni mucho menos un criterio favorable. De esta forma, la Sala Constitucional mantiene y protege su propia línea jurisprudencial respecto a la prohibición de la aplicación de la figura del derecho administrativo del silencio positivo en materia de medio ambiente. Sobre el particular dispuso:

"En relación con segundo aspecto -aplicación del silencio positivo-, el párrafo final del artículo 17 indica: “(...) Las citadas instituciones deberán contestar en un plazo máximo de 10 días hábiles improrrogable de su notificación, de lo contrario se deberá continuar con el trámite correspondiente." En primer lugar es oportuno indicar que la norma no indica que la falta de respuesta suponga la verificación del silencio positivo; lo que

\footnotetext{
${ }^{13}$ Hernández Valle, Rubén. La problemática de las sentencias normativas, en La Jurisdicción constitucional y su influencia en el Estado de Derecho, San José, EUNED, 1996.
} 
señala es que el trámite continuará. El hecho de que el trámite continúe, no significa que opere el silencio positivo, es decir, que se acoja o apruebe la solicitud en trámite. En ese sentido, este Tribunal ha indicado en varias sentencias (5745-1999 y 5245-2002 entre otras) que el principio del silencio positivo no opera de pleno derecho cuando se trata de procedimientos o actuaciones donde esté en juego la protección del medio ambiente. Si la Administración omite pronunciarse sobre una solicitud o permiso para realizar una determinada actividad, debido a la particular importancia y trascendencia del tema ambiental, prevalece el interés público representado por el Estado en cuanto a su obligación de tutelar el derecho a un medioambiente sano y ecológicamente equilibrado, sobre el interés privado de terceros. Es claro que los asuntos ambientales tienen la particularidad, sobre otros de puro derecho que, generalmente, para su conocimiento y resolución se requiere análisis técnicos, evaluaciones, estudios fácticos, lo que no siempre es posible realizar en un período de un mes".

Por su parte, a través del voto 2009-17155 la Sala Constitucional dispuso la constitucionalidad del artículo 6 del Código de Minería respecto a la declaratoria de utilidad pública de la actividad minera, siempre y cuando sea interpretada a la luz del artículo 50 constitucional. Por medio de esta resolución el tribunal constitucional mantiene y consolida su línea de jurisprudencia respecto a la obligación de exigir evaluación de impacto ambiental a todas aquellas actividades, obras o proyectos que puedan tener un impacto negativo sobre el ambiente. Al efecto manifestó:

"Así las cosas, quedó claro para el legislador, que si bien su intención era incentivar una actividad económica que estaba abandonada en nuestro país por una deficiente legislación, no se dejaba de lado la importancia de prevenir cualquier daño que se produjera al ambiente y por ello se exigió un estudio previo a cualquier exploración o explotación minera. Como se indicó anteriormente, la Sala reconoce la necesidad de una inter-relación equilibrada entre los elementos críticos del desarrollo económico (turismo, inversión, empleo, infraestructura, finanzas sanas y sistema tributario) de la política social (educación, salud, seguridad) y de la protección medioambiental. Sin embargo, la responsabilidad consiste en equilibrar la protección del ambiente, el desarrollo económico y las actividades de los particulares, que justifique la intervención del Estado. Lo anterior, por cuanto una protección excesiva del ambiente que anule toda actividad económica, puede hacer incurrir a los particulares en costos desproporcionados e innecesarios, tornando algunas actividades productivas en ruinosas y generando pobreza y desempleo, lo cual impactaría negativamente a la gente. Pero de igual modo, una actividad económica descontrolada e irresponsable puede producir un daño irreversible en el ecosistema, razón por la cual se impone la aplicación del principio "in dubio pro natura", en el sentido de que si existe duda sobre si una actividad produce o no daños al ambiente, debe priorizarse en su protección y en consecuencia, limitarse o prohibirse dicha actividad. No obstante, la determinación de esa duda, no puede, ni debe, quedar al arbitrio de los grupos sea cual sea, sino de estudios técnicos, pues este aplicará cuando haya peligro de daño grave o irreversible en el ambiente. Precisamente el artículo 3 del Código de Minería, dispone que todo permiso de exploración o concesión de explotación requiere de previo el análisis y la aprobación del estudio o evaluación de impacto ambiental. Lo anterior, por cuanto sin duda alguna los efectos que produce un proyecto minero requieren de una evaluación de 
impacto ambiental por las consecuencias que se suelen producir en el desarrollo de la industria minera, y esta evaluación previa determinará si el proyecto es ambientalmente viable. En consecuencia de lo expuesto, la declaratoria de utilidad pública de una actividad como la minería, no resulta inconstitucional per se, siempre y cuando sea interpretada a la luz de lo dispuesto en el artículo 50 de nuestra Constitución Política según los términos expuestos”.

Ahora bien, siguiendo la clasificación propuesta por HERNÁNDEZ VALLE desarrollada en la sección primera de este trabajo, se expondrán y analizarán a continuación sentencias interpretativas-normativas en materia ambiental que califican tanto de aditivas como de sustitutivas.

\subsection{Sentencias aditivas}

En un primer orden de ideas se encuentran las sentencias normativas aditivas, sea aquellas relacionadas con la inconstitucionalidad por omisión. En relación a ellas, la Sala Constitucional a través del voto 2003-10421 expuso:

"Este Tribunal, en el ejercicio del control de constitucionalidad, ha aplicado el principio de conservación de las normas, para dictar sentencias anulatorias cuando la infracción constitucional sea insuperable, sea por la confrontación del texto de la norma, de sus efectos, de su interpretación o aplicación por las autoridades públicas, con las normas y principios constitucionales (art. 3). En la medida en que la constitucionalidad de la norma sea superable mediante su interpretación conforme o por otro medio, puede y debe evitarse la drástica solución anulatoria. El legislador no dispuso regulaciones concretas sobre las sentencias estimatorias en los casos en que la violación constitucional haya sido declarada por causa de una omisión, por lo que la Sala, en algún caso, ha aplicado analógicamente el párrafo segundo del artículo 49 de la Ley de la Jurisdicción Constitucional, referido al amparo, el cual dispone que "si el amparo hubiere sido establecido para que una autoridad reglamente, cumpla o ejecute lo que una ley u otra disposición normativa ordena, dicha autoridad tendrá dos meses para cumplir con la prevención" (v. sentencia \#1463-90 de 14:30 hrs. de 30 de octubre de 1990). Sin embargo, la Sala considera que dicha disposición, si bien resulta aplicable a los casos en que ha existido una omisión de reglamentar, determinada en la vía del amparo o de la acción de inconstitucionalidad, no lo es, necesariamente, en casos como el presente, en que la sentencia estimatoria de la acción detecta una omisión normativa, o un vacío, que incluso puede ser consecuencia de un error del que dicta la norma, la cual es, precisamente, la causa de la inconstitucionalidad y que puede ser subsanado por otros medios. En efecto, el legislador dejó en manos del Tribunal la solución a las omisiones inconstitucionales y a las inconstitucionalidades por omisión, para lo cual el Tribunal ha de disponer lo procedente, de conformidad con el artículo 14 de la Ley de la Jurisdicción Constitucional, según el cual, a falta de disposición expresa, se aplicarán los principios del derecho constitucional, así como los del derecho público y procesal generales o, en su caso, los del derecho internacional o comunitario y, además, por su orden, la Ley General de la Administración Pública, la Ley Reguladora de la Jurisdicción Contencioso Administrativa y los Códigos Procesales. Como la inconstitucionalidad radica en la omisión dicha, no así en el contenido de las normas mismas, tampoco no cabe aplicar los efectos anulatorios previstos en el artículo 88 de la Ley de la Jurisdicción Constitucional 
porque dicha omisión no puede tener como consecuencia una sentencia anulatoria, ya que es obvio que a las omisiones no es aplicable anulación alguna, sino que la omisión sólo debe ser reparada o satisfecha".

Bajo el anterior fundamento jurídico y ante acción de inconstitucionalidad en contra de los artículos 128, 129, 140, 141, 152 y 153 del Reglamento al Código de Minería, Decreto Ejecutivo 29300-MINAE, la Sala Constitucional determinó que se encontraba ante una infracción constitucional por omisión disponiendo al efecto:

"A pesar de la simplicidad del argumento constitucional de fondo del cual se deriva la inconstitucionalidad señalada, el asunto entraña una particular situación, desde el punto de vista de los efectos de la sentencia, ya que una aplicación pura y simple de lo dispuesto en el artículo 88 de la Ley de la Jurisdicción Constitucional conduciría a la drástica solución de disponer la anulación de los artículos 129 y 153 del Decreto; sin embargo, ninguno de los requisitos contemplados en esas disposiciones es impugnado, ni la Sala encuentra inconstitucionalidad alguna. Lo que ocurre, desde el punto de vista de la estructura normativa, no es que dichos artículos sean inconstitucionales, sino que faltó disponer la norma que dice que para la aprobación de los proyectos menores y específicos previstos en los artículos 128 y 152 del Decreto es necesario el estudio de impacto ambiental, la cual existe en el ordenamiento, derivada del artículo 50 constitucional, de los instrumentos internacionales citados supra y de la jurisprudencia de la Sala, con lo cual, ha de interpretarse, en la misma forma que este Tribunal lo ha hecho en la vía de amparo, que es obligatorio el estudio de impacto ambiental para otros casos concretos, igualmente, para los procedimientos menores y específicos".

En virtud de lo anterior, la Sala Constitucional declaró con lugar la acción, únicamente en cuanto a la inconstitucionalidad de la omisión de exigir evaluación de impacto ambiental y su correspondiente aprobación por parte de la Secretaría Técnica Nacional Ambiental como requisito previo a las solicitudes de permisos mineros para proyectos menores y específicos. ${ }^{14}$

También es posible citar el voto constitucional número 2007-3923 que declaró la inconstitucionalidad del concepto jurídico "bosque" del artículo 28 de la Ley Forestal, en cuanto a la omisión relativa de establecer medidas precautorias que aseguraran la protección del ambiente, específicamente por dejar por fuera del concepto "bosque" ecosistemas forestales de todas aquellas especies no autóctonas y las áreas inferiores a dos hectáreas. En lo que interesa expuso la Sala:

"Ciertamente la reforma a esta ley, que se produjo mediante ley No. 7575 de 5 de febrero de 1996, tuvo como fin el promover e incentivar la reforestación en nuestro país, para lo cual intentó librar de trámites innecesarios la corta de determinado tipo de árboles. No obstante lo anterior, considera este Tribunal que al haber pasado la ley de una definición amplia de bosque, con mayor cobertura de protección, a una tan restringida en cuanto a especies y superficie, hace que la protección dada con anterioridad al ambiente, haya sido disminuida sin una justificación razonable, que vaya más allá de la necesidad de

${ }^{14} \mathrm{Al}$ respecto ver los votos constitucionales 2002-1221 y 2003-6312. 
reforestar y eliminar las trabas administrativas, como un incentivo de esta actividad, pero sin asegurar previamente, que está en su ejecución, no pusiera en peligro el ambiente. Debemos recordar que nuestro país ha suscrito compromisos internacionales de protección al ambiente y uno de los principios que debe resguardar es el principio precautorio ya citado, según el cual, la prevención debe anticiparse a los efectos negativos, y asegurar la protección, conservación y adecuada gestión de los recursos. Consecuentemente, este principio rector de prevención, se fundamenta en la necesidad de tomar y asumir todas las medidas precautorias para evitar o contener la posible afectación del ambiente o la salud de las personas. De esta forma, en caso de que exista un riesgo de daño grave o irreversible -o una duda al respecto-, se debe adoptar una medida de precaución e inclusive posponer la actividad de que se trate. Sin duda alguna, para ello se requiere de una posición preventiva, activa y alerta por parte de la administración, pues una conducta posterior y únicamente sancionatoria, haría nugatoria cualquier acción efectiva que se pretenda a favor del ambiente, donde una vez. producido el daño, difícilmente puede ser restaurado y sus efectos nocivos pueden afectar no sólo a nivel nacional, sino mundial. Y es que este, es uno de los principios rectores en materia ambiental, la prevención. Con ello no se trata tampoco de evitar el desarrollo y detener el progreso y la economía, sin embargo se debe procurar un equilibrio que le permita al ser humano desarrollarse, pero también vivir y disfrutar ese desarrollo, al cual tienen derecho no sólo las generaciones actuales, sino también las venideras. (...) Según el análisis practicado al artículo impugnado, el legislador modificó el concepto de bosque a partir del cual se desarrolla la protección, restricciones y permisos otorgados en la Ley Forestal -como es el caso del artículo 28 en cuestión "Excepción de permiso de corta"-, de tal manera que, restringió sin fundamento técnico, el concepto anterior de bosque existente en la ley previo a su reforma. De modo que fueron dejadas sin protección vía ley, las especies no autóctonas y las áreas inferiores a dos hectáreas que constituyeran bosque, trayendo como consecuencia, que a través del artículo 28 impugnado, no se requiera de permiso para talar, ni siquiera de inspección previa, que permita asegurar que se trata del supuesto que la norma quiso incentivar, toda plantación forestal, sistema agroforestal o cualquier árbol plantado, quedando expuestas áreas que por su ubicación, cantidad y la función que han ejercido durante muchísimos años, amerita la conservación y regulación de su tala, independientemente de la naturaleza de su especie y de la naturaleza del terreno donde se ubique. Así las cosas, esta Sala considera de conformidad con lo expuesto, que en este caso, se produce una inconstitucionalidad por omisión relativa”.

Ante la señalada omisión relativa, la Sala Constitucional dejó claro su competencia para declarar su inconstitucionalidad, pero dispuso que una violación de esta naturaleza debe ser subsanada por la Asamblea Legislativa, extendiendo la aplicación de la ley a los casos no contemplados expresamente por ella incluyendo las especies y áreas que quedaron desprotegidas en el concepto de bosque actual, así como tomar medidas de prevención y control sobre las áreas en las que son permitidas la tala. Por ello, estimó que el artículo 28 cuestionado lesionó el artículo 50 de la Constitución Política, pero a fin de no violentar el principio de separación de poderes, procedió a otorgar un plazo prudencial a la Asamblea Legislativa para la subsanación de la violación indicada. 
Como puede observarse, en las dos situaciones antes expuestas y por tratarse de inconstitucionalidades por omisión, mediante sentencias interpretativas la Sala Constitucional mantuvo la vigencia de las normas impugnadas.

En el primer caso bajo análisis, mediante una interpretación conforme a la Constitución, la Sala Constitucional exige la evaluación de impacto ambiental a proyectos mineros menores y específicos, ratificando su línea jurisprudencial y evitando con ello una regresión respecto a su propia jurisprudencia. En el segundo, ante la reducción del nivel de protección ambiental obtenido previamente mediante la ley forestal derogada, y tal y como exigen los principios precautorio, objetivación, progresividad y no regresión ambiental, el tribunal constitucional opta por declarar la inconstitucionalidad por omisión de la definición de bosque contenida en la actual ley forestal, otorgándole plazo a la Asamblea Legislativa con el fin que modifique dicha definición, situación aún pendiente por parte del órgano parlamentario.

\subsection{Sentencias sustitutivas}

Las sentencias estimatorias sustitutivas son aquellas que introducen nuevas normas mediante la supresión de determinadas palabras o párrafos de una norma o texto, de manera tal que cambia el contenido normativo del enunciado original.

Muestra de ello es la sentencia constitucional número 2011-16938 que declaró la inconstitucionalidad de varias frases de los artículos 2 y 3 del Decreto Ejecutivo número 35803-MINAE - Criterios Técnicos para la identificación, clasificación y conservación de humedales - estableciendo en ambos casos una nueva forma constitucional de lectura para dichos artículos, al efecto, la Sala Constitucional dispuso:

"El Patrimonio Natural del Estado es un bien jurídico, definido e individualizado en nuestro ordenamiento jurídico, cuyos terrenos que lo conforman según la legislación ambiental, no necesitan de una declaratoria de área silvestre protegida para ser objeto de protección por parte de la Administración. Lo anterior no obsta la obligación de la Administración competente de darles las clasificaciones que científica y técnicamente correspondan, para su debida protección y preservación como áreas silvestres protegidas. Esto es materia de interés público y nacional que urge y no puede quedarse indefinidamente sin resolver. Con base en lo expuesto se declara inconstitucional del artículo 2 del Decreto Ejecutivo No. 35803-MINAET la frase "son aquellos que cuenten con una declaratoria de Área Silvestre Protegida”; en adición, para que la norma preserve su sentido se elimina la conjunción "que", luego de la palabra "continentales". También se declara inconstitucional del artículo 3 del Decreto supracitado la frase "son aquellos que cuenten con una declaratoria como Área Silvestre Protegida”; en adición, para que la norma preserve su sentido también se elimina la conjunción "que”, luego de la palabra "marinos". De esta manera se preserva la voluntad del Poder Ejecutivo en el sentido que los citados humedales forman parte del Patrimonio Natural del Estado. En relación con el ordinal $3^{\circ}$ se deja la frase "los cuales serán administrados por el MINAET a través del Sistema Nacional de Areas de Conservación”, porque todos los ecosistemas de humedales marinos son áreas inalienables de la zona marítimo terrestre, de dominio público y bienes de la nación, por lo que solo pueden ser administrados por el Estado a 
través de los órganos que indique la ley. Por consiguiente, los artículos supracitados deberán leerse de la siguiente forma:

"Articulo $2^{\circ}$ - Ecosistemas de Humedales Continentales. Los ecosistemas de humedales continentales forman parte del Patrimonio Natural del Estado".

"Artículo 3- Ecosistemas de Humedales Marinos. Los ecosistemas de humedales marinos forman parte del Patrimonio Natural del Estado, los cuales serán administrados por el MINAET a través del Sistema Nacional de Áreas de Conservación".

Por su parte, y siempre dentro de las sentencias sustitutivas que introducen nuevas normas, es posible citar el voto constitucional 2012-5593 que eliminó la palabra "privada" del artículo 24 del Decreto Ejecutivo 31136-MINAET - Reglamento de Procedimientos del Tribunal Ambiental Administrativo- debiendo interpretarse que la audiencia allí establecida y llevada a cabo por el Tribunal Ambiental, una vez concluida la etapa de investigación, es pública, salvo resolución razonada en contrario:

"El Reglamento de Procedimiento del Tribunal Ambiental Administrativo regula el procedimiento que se da ante dicho Tribunal, en tanto órgano administrativo desconcentrado del Ministerio del Ambiente y Energía y con ocasión de una denuncia ambiental. Según el artículo 24 de dicho reglamento, luego de concluida la etapa de investigación el Tribunal dicta la apertura del procedimiento administrativo citando a las partes a una audiencia, la cual se dice es "oral y privada". Sin embargo, en atención a que no se está en una etapa preliminar de investigación sino que ya la investigación ha concluido, y en atención al derecho de participación ciudadana en materia ambiental, resulta inconstitucional que se establezca -igual que en el resto de procedimientos administrativos que no tratan materia ambiental- que dicha audiencia será "privada". Antes bien, la regla en esta materia debe ser la audiencia pública, y la excepción, que mediante resolución fundamentada se declare su privacidad. Extrapolando lo que sucede en otra clase de procedimientos donde los juicios son públicos, y guardando las distancias del caso -sea el proceso contencioso administrativo según el artículo 99 del Código Procesal Contencioso Administrativo o el proceso penal según el artículo 330 del Código Procesal Penal-, el Tribunal Ambiental Administrativo puede igualmente decretar, mediante resolución motivada, que parte de la audiencia se desarrolle de forma privada. Esto es así, pues, a diferencia de otro tipo de procedimientos administrativos donde la regla es la privacidad de las audiencias, en este caso nos encontramos con una materia donde el lesionado o la víctima es toda la comunidad, así que no puede dársele el mismo tratamiento en cuanto a este aspecto. Recuérdese, en los términos dichos en el considerando anterior, que la lesión al derecho fundamental al ambiente lo sufre tanto un individuo en particular como toda la comunidad, así que toda persona debe tener el derecho de poder participar en este tipo de procedimientos administrativos ante el Tribunal Ambiental Administrativo, por lo menos, teniendo el derecho de asistir a las audiencias. La participación comunal en la toma de decisiones en materia ambiental forma parte del debido proceso sustantivo al que debe sujetarse dicho Tribunal, y a la vez es una forma de expresión de la democracia participativa y una forma de hacer respetar las garantías establecidas en el artículo 50 de la Constitución Política. Así entonces, el hecho de que el artículo impugnado establezca la privacidad de la audiencia, implica una afrenta al derecho de participación en materia ambiental, 
consagrado en nuestra Constitución Política. Conclusión.- Dado que la privacidad de la audiencia establecida dentro del procedimiento ordinario administrativo del Tribunal Ambiental Administrativo resulta incompatible con el derecho de participación ciudadana, especialmente en asuntos ambientales, procede la declaratoria de inconstitucionalidad de la palabra "privada" contenida en el artículo 24 del Reglamento de Procedimientos del Tribunal Ambiental Administrativo. Por lo tanto esta acción se declara con lugar, se anula la palabra "privada", debiendo interpretarse que la audiencia allí establecida y llevada a cabo por ese Tribunal, una vez concluida la etapa de investigación, es pública, salvo resolución razonada en contrario. Sin embargo, de conformidad con lo dispuesto por el artículo 91 de la Ley de la Jurisdicción Constitucional, a efectos de no afectar los procedimientos administrativos ya llevados a cabo, se dimensionan los efectos de tal declaratoria en el sentido de que surte efectos generales a partir de la fecha de esta resolución”.

Como puede observarse, en las dos situaciones antes analizadas el tribunal constitucional opta por declarar la inconstitucionalidad, ya sea de frases o bien de palabras dentro de una norma jurídica de carácter ambiental, las cuales en lo demás, mantienen su vigencia. Sin embargo son modificadas por los jueces constitucionales en su rol de legislador positivo, adquiriendo con ello una nueva connotación y sentido a la luz del derecho de la constitución.

Por su parte, y tratándose de sentencias sustitutivas que ponen en vigencia normas derogadas, vale la pena citar el voto constitucional 1993-3459, que vía interpretación, declaró la vigencia de la Ley de Cercas Divisorias y Quemas número 121 del 26 de octubre de 1909. Dicha sentencia si bien ratificó la derogatoria del artículo 5 párrafo 5, en cuanto a la responsabilidad penal debido a la promulgación de los Códigos Penales de 1924, 1941 y 1979, lo cierto del caso es que mantuvo la vigencia de los demás artículos aplicables a cualquier otro tipo de responsabilidad. Al efecto dispuso la Sala Constitucional:

"Esta Sala participa en un todo de las conclusiones a que llega la Procuraduría General de la República en la contestación que presentó a la audiencia que le fue conferida, pues resulta indudable que la sucesión de leyes en el tiempo, referidas a "quemas de maleza, rastrojos y otros productos de la tierra" y la derogatoria genérica contenida en los códigos Penales de 1924, 1941 y 1970, en relación con las leyes punitivas referidas a los hechos previstos en esos ordenamientos, han producido la derogatoria de la norma consultada. En la norma consulta se reprime a quien hiciere "quemazones en los campos" y en el artículo 555 inciso $21^{\circ}$ del Código Penal de 1924, se reprimió con multa menor o arresto en sus grados cuarto a sexto, al que infringiere las reglas para la quema de maleza, rastrojos u otros productos de la tierra. La capacidad de subsunción de la conducta de quemar los campos, en ambas normas, es idéntica, razón por la que operó a esa fecha la derogatoria contenida en el artículo 561 del citado Código, al disponerse: "Quedan derogadas todas la leyes punitivas referentes a los hechos previstos y penados en este Código, aún las que hayan especializado la represión de determinados delitos. En el Código de Policía de 1941, en el artículo 161, se dispuso el castigo, con arresto de uno a sesenta días o multa de dos a ciento veinte colones, (inc.1o.) a los que contravinieren las disposiciones encaminadas a prevenir incendios o a evitar su propagación y (inc. 3o.) a quien infringiere las reglas sobre quema de malezas, rastrojos 
u otros productos de la tierra, disponiéndose a la vez, en el artículo 173 de ese Código, la derogatoria de las disposiciones de carácter punitivo, de todas las leyes referentes a los hechos previstos en ese ordenamiento legal. También en el artículo 403 del Código Penal vigente se penaliza con tres a treinta días multa, al que contraviniere las disposiciones encaminadas a prevenir incendios o a evitar su propagación (inc. 1o.) y a quien infringiere las reglas sobre quema de malezas, rastrojos u otros productos de la tierra (inc. 2o.) y en el 414, se deroga expresamente el Código Penal y de Policía, ambos de 21 de agosto de 1941 y todas las disposiciones legales que los adicionan y reforman, quedando igualmente derogadas en sus disposiciones de carácter punitivo, todas las leyes referentes a los hechos previstos y penados en ese Código".

De manera similar, por medio de la resolución 2008-12109, la Sala Constitucional dispuso la vigencia del decreto ley número 65 del 28 de julio de 1888, por medio del cual el legislador ordenó proteger una de la zonas en las que se encuentran las nacientes de agua que abastecen a los habitantes de las provincias de Heredia, Alajuela y parte de San José. En esa ocasión, la Sala Constitucional expuso:

"Partiendo de lo externado en los considerandos anteriores, esta Sala considera que en el caso concreto se constata una violación a lo dispuesto por el artículo 50 constitucional, la cual es achacable al Estado y a las municipalidades recurridas. En lo que respecta al Estado Costarricense, se tiene por probado que a lo largo de los años, éste no ha realizado las labores correspondientes a efecto de delimitar la zona comprendida por la ley número 65 de mil ochocientos ochenta y ocho, con el fin de garantizar que en dicho lugar no se llevara a cabo ningún tipo de actividad humana y cumplir así con la pretensión que tenía el legislador al momento de dictar la norma de cita. Dicha inercia se mantiene incluso hasta la actualidad, pues el Ministerio de Ambiente y Energía , como autoridad encargada de velar por los recursos naturales del país, ha incumplido con su labor de delimitar y vigilar en forma efectiva, la franja de terreno establecida por la ley número 65, ello a pesar de que el legislador afectó dicha zona al dominio público con el fin de crear un área libre de cualquier tipo de injerencia de particulares, intención que no se ha cumplido a la fecha, ya que en los autos consta que incluso se han otorgado permisos de construcción en el terreno de cita. En el caso de las municipalidades accionadas, se deduce de la prueba aportada al expediente que dichas corporaciones han otorgado permisos de construcción en la zona comprendida por el decreto ley número 65, situación que vulnera no sólo el deseo que tenía el legislador al momento de promulgar la norma de cita, sino que además violenta lo dispuesto por el artículo 50 constitucional, en razón de lo expuesto anteriormente. Conviene mencionar, que si bien en la ley número 65 no se establece claramente el grado de limitación al que estaba sometida la zona establecida por dicha ley, lo cierto es que en aplicación del principio de indubio pro natura, y tomando en cuenta el espíritu de la norma de cita, esta Sala considera que debe entenderse que dicha protección es total, por lo que no puede otorgarse ningún tipo de permiso o concesión en dicha franja de terreno. Asimismo, estima este Tribunal que ninguna de las autoridades recurrida puede alegar desconocimiento de lo dispuesto por la ley número 65, pues si bien ha transcurrido más de un siglo desde que la misma fuera creada, lo cierto es que dicha norma mantiene aún su vigencia, tal y como se deduce de la Opinión Jurídica número OJ-118-2004 de la 
Procuraduría General de la República. Así, en razón de lo expuesto anteriormente, lo procedente es acoger el recurso en cuanto a este extremo, ordenando al Ministerio recurrido coordinar lo correspondiente con el Instituto Geográfico Nacional para delimitar físicamente la zona comprendida por la ley antes citada, para luego recuperar los terrenos que se encuentren ahí y que estén siendo ocupados por particulares; y a las municipalidades accionadas abstenerse de otorgar cualquier tipo de permiso dentro del perímetro establecido por la ley número 65 ".

En cuanto a estas últimas dos sentencias debe considerarse además que en virtud de la obligación estatal de cumplir y hacer cumplir de manera sostenida y recurrente la legislación ambiental, su incumplimiento e inobservancia sistemática además de producir ineficacia, constituye un tipo especial de regresión ambiental. ${ }^{15}$ De esta forma, el órgano constitucional al determinar la vigencia de dichas normas y su carácter vinculante, cumple con su obligación constitucional respecto a garantizar el derecho a un ambiente sano y equilibrado.

\section{Conclusión}

A manera de conclusión general sería posible afirmar que la técnica de las sentencias interpretativas se posiciona como un instrumento esencial e imprescindible con el que cuenta el juez constitucional para garantizar el orden público ambiental y con ello mejorar la eficacia del derecho ambiental.

\section{Bibliografía}

Aguilar Rojas, Grethel e Iza, Alejandro, Derecho Ambiental en Centroamérica, Tomo I, UICN, 2009.

Arguedas Ramírez, Carlos Manuel, La interpretación judicial y la Sala Constitucional de la Corte Suprema de Justicia de Costa Rica, en Revista de Estudios Constitucionales, volumen 1, número 1, 2003, Chile, 2003.

Comisión Interamericana Derechos Humanos, Lineamientos para la elaboración de indicadores de progreso en materia de derechos económicos, sociales y culturales CIDH, accesible en: http://www.cidh.oas.org/countryrep/IndicadoresDESC08sp/ Indicadoresindice.sp.htm

Ferrer Mac-Gregor, Eduardo, Interpretación conforme y control difuso de convencionalidad. El nuevo paradigma para el juez mexicano, accesible en: http://biblio.juridicas.unam.mx/libros/7/3033/14.pdf

Gonzalez Ballar, Rafael, Reflexiones para la interpretación de la no regresión, en El Principio de no regresión ambiental en el derecho comparado latinoamericano, PNUD, 2013.

\footnotetext{
${ }^{15} \mathrm{Al}$ respecto puede consultarse el artículo de este mismo autor denominado Test de Regresividad Ambiental publicado en la Revista Internacional de Direito Ambiental (RIDA) número 6, Brasil, 2003, accesible en la siguiente dirección:

http://maestriaderechoambientalucr.files.wordpress.com/2013/12/rida_vol_ii_n06_set-dez_2013.pdf
} 
Gonzalez Ballar, Rafael, El aporte del proceso de interpretación en la construcción del derecho ambiental, en Temas de Derecho Ambiental, Editorial Investigaciones Jurídicas, San José, 2011.

Hernández Valle, Rubén, La interpretación constitucional en Costa Rica, Biblioteca Jurídica UNAM, 1996.

Hernández Valle, Rubén, La problemática de las sentencias normativas, en La Jurisdicción constitucional y su influencia en el Estado de Derecho, San José, EUNED, 1996.

Jinesta Lobo, Ernesto, Interpretación y aplicación directa del derecho de la Constitución por el juez ordinario" en Revista Ivstitita, año 10, número 118-119, octubrenoviembre 2006.

Peña Chacón, Mario, Test de regresividad ambiental, en Revista Internacional Direito Ambiental (RIDA), número 6, Brasil, 2013.

Peña Chacón, Mario, El Principio de no regresión ambiental en el derecho comparado latinoamericano, PNUD, 2013.

Peña Chacón, Mario, Hacia una nueva hermenéutica ambiental, en Lex, Difusión y Análisis, año XII, número 222, México, diciembre 2013.

Solano Carrera, Luis Fernando, A veinte años de la Sala Constitucional: reflexiones sobre impactos, riesgos y desafíos, ponencia para el XV Informe del Estado del Nación en Desarrollo Humano Sostenible, San José, 2010.

"LA REVISTA INNOVARE NO SE HACE RESPONSABLE EN NINGÚN CASO DE LOS CONTENIDOS, DATOS, CONCLUSIONES U OPINIONES VERTIDAS EN LOS ARTÍCULOS PUBLICADOS, SIENDO ESTA RESPOSABILIDAD EXCLUSIVA DEL (DE LOS) AUTOR (AUTORES)" 